friendship which made the occasion one of much more than purely scientific value. This kind of atmosphere is perhaps less easily created at an ordinary international conference, and we hope that this will not be the last occasion on which a scientific society is invited to hold a meeting in another country.

\section{C. Beadle}

\section{MOUNT HOPE AND ITS DAIRY CATTLE}

$\mathrm{T}$ HE increase of milk production is one of the desiderata that is commonly accepted as necessary, and one of the equally commonly accepted ways of securing an increase is by the use of a proven sire. This is the more necessary because it has been said by no less an authority than Robert Boutflour that the average production during a lactation is little, if any, more to-day than it has been for a very long time.

It is to this end that the Mount Hope Farm was established, and a complex of investigations into the laws of inheritance among mice, poultry and dairy cattle began. Mr. Parmalee Prentice has now described these investigations (Agric. History, Oct. 1946). The work with dairy cattle started in 1916 when the first were bought, but contagious abortion delayed the start of real work on breeding until the herd had been purged of this disease, by which time (1924) a young Guernsey herd had been acquired which was thought likely to be good. For various causes a satisfactory bull did not appear, and in 1925 a bull was bought because he ranked well according to the system of valuing dairy bulls developed at the Maine Agricultural Experiment Station. This system is based on a comparison of a bull's mates and of his daughters; if the daughters' milk yield was higher the bull was advantageous, if lower the bull was detrimental. The amount of the increase was considered to be a measure of the bull's influence on milk yield.

Misfortune followed the choice, for the bull became impotent and a new bull was selected on the Turner measure for proven sires; but this was found unsatisfactory, and this particular system is no longer used "because it has been found that it over-estimated the inheritance which the sire contributed to its offspring"; and Mr. Parmalee Prentice and his coworkers found it conceivable that the daughters of this bull were good "not only because his influence was good but also because their dams had contributed as much as the sire"-which seems not unreasonable.

They then proceeded to work out a system of their own which they named the Mount Hope 'index', "a correct method of determining a bull's breeding worth from his daughters' records after allowance is made for the dam's influence upon the daughters' productivity". The index was first announced in $\mathbf{1 9 2 7}$ and has now been before the world for twenty years.

"Bull indexes are computed by comparing the production records of the daughters and mates of the bull. In oreler to compare the production of the daughters with the production of their dams and to make comparisons between other cows of different ages, our statistics of milk production since 1936 .. are always in terms of the mature equivalent. The index is then always applied to a comparatively small number of dam-daughter pairs. Moreover seasons vary; food and management are different in different barns and frequently change in the same barn. The physical condition of the cattle varies, and the result of it all is that though we are able with assurance to tell a good cow from a poor one and in general to tell how good a particular cow is, we are never able in measuring production records to tell with scientific precision the productive ability of a particular cow."

In many places the Mount Hope index has been accepted and is being used. In others, and perhaps the majority, the index is regarded with some scepticism. The need for proven sires and the sons of proven sires in dairy cattle breeding is fairly generally accepted, and records have been adopted so that performance may rank alongside 'pedigree'one of the qualifications of which the Mount Hope workers are most critical. There has been a good deal of controversy about the Mount Hope dairy cattle and the Mount Hope index, and the essay by Mr. Parmalee Prentice in Agricultural History of October 1946 tells the whole story of the work that has been done there. The quarterly is the organ of the American Agricultural History Society, the offices of which are at Room 3870, South Agricultural Building, Washington 25, D.C.; and the annual subscription is four dollars.

G. E. Fusserl

\section{RELEASE OF INFORMATION ON ATOMIC ENERGY*}

$T$ HE National Research Council of Canada is making available a number of reports, recently taken off the secret list, on subjects in the fields of theoretical physics and applied mathematics. These reports, which are either too long for journals or are summaries of other work, will be reproduced by the multilith process and will be available at a small charge from the Plans and Publications Section of the National Research Council, Ottawa.

Much material in the hands of the Council is being published in Canadian scientific journals, but the titles mentioned below represent a few which for special reasons cannot be dealt with in that way. LIST OF DEOLASSIFIED REPORTS

$\begin{array}{lll}\text { MT-1 } & \text { The Functions } E_{n}(x)=\int_{1}^{\infty} e^{-x w} u^{-n} d x & \text { G. Placzek } \\ \text { MT-12 } & \begin{array}{l}\text { Elementary Approximation in the } \\ \text { Theory of Neutron Diffusion } \\ \text { Notes on Diffusion of Neutrons without } \\ \text { Change in Energy }\end{array} & \begin{array}{l}\text { P. R. Wallace } \\ \text { and J. LeCaine }\end{array} \\ \text { GT- Placzek and } \\ \text { G. Volkotf }\end{array}$

MT-131 A Table of Integrals involving

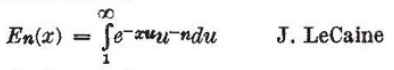

MT-88 Influence of a Small Black Sphere upon the Neutron Density in an Infinite Non-Capturing Medium

MT-232 Influence of an Air Gap surrounding a Small Black Sphere upon the Linear MT-93 $\begin{array}{r}\text { Sxtrapolation Length of the Neutron } \\ \text { Density in the Surrounding Medium } \\ \text { Influence of a Large Black Sphere upon } \\ \text { the Neutron Density in an Infinite }\end{array}$ MT-93 $\begin{array}{r}\text { Sxtrapolation Length of the Neutron } \\ \text { Density in the Surrounding Medium } \\ \text { Influence of a Large Black Sphere upon } \\ \text { the Neutron Density in an Infinite }\end{array}$

B. Davison the Neutron Density in an Inflnite Non-Capturing Medium

MT-112 Angular Distribution due to an Isotropic Point Source and Spherically Symmetrical Eigen-Solutions of the Transport Equation

MT-135 Influence of a Large Black Cylinder upon the Neutron Density in an Inflnite Non-Capturing Medium

MT-124 Large Spherical Hole in a Slightly Capturing Medium MT-136 Neutron Density at the Centre of a

B. Davison

B. Davison

B. Davison

B. Davison

B. Davison

B. Davison

- British declassifled reports are announcedlin Nature, March 22, p. 411 . 